\title{
¿QUÉ ES LA HISTORIA ANTROPOMÉTRICA?
}

JOHN KOMLOS

Universidad de Munich

Cabe pensar que la estatura media que se alcanza a una determinada edad o la estatura media adulta que alcanza la población es un indicador histórico de la experiencia nutritiva de los individuos que componen esa población. Este tipo de razonamiento se basa en investigaciones médicas, que han demostrado sin lugar a dudas que la ingesta nutritiva acumulada de una población influye poderosamente en su estatura media y que el entorno epidemiológico también desempeña un papel importante. Por lo tanto, la estatura física puede utilizarse como un indicador de cómo se desarrolla el organismo humano en su entorno socioeconómico. Concretamente, la situación nutritiva $-\mathrm{y}$, por lo tanto, la estatura - está relacionada con el consumo de alimentos y, por consiguiente, con la renta familiar real y, por lo tanto, con los salarios y con los precios y, por lo tanto, con el nivel de vida, concebido en términos generales. Por consiguiente, podemos utilizar la estatura como un indicador aproximado de estas variables económicas ${ }^{1}$.

La historia antropométrica nació a mediados de los años 70 en conjunción con los intentos de los economistas de cuantificar los cambios que ha experimentado el nivel de vida en los últimos doscientos años en las economías en las que o no existian indicadores más convencionales del bienestar, como el PNB per cápita, o en las que éstos eran controvertidos. A diferencia de lo que ocurre con los salarios reales, la evidencia antropométrica es abundante y tiene, además, la ventaja de referirse a grupos, como los niños, las amas de casa, los campesinos que trabajan para su subsistencia, los aristócratas y los esclavos,

' John Komlos (1989) cap. 1. 
a los que pocas veces o nunca se aplican los conceptos económicos convencionales ${ }^{2}$.

Los primeros resultados mostraron que los soldados americanos que participaron en la Guerra de la Independencia eran dos pulgadas más altos que los soldados británicos de la misma edad. Es decir, las ventajas nutritivas del Nuevo Mundo ya eran evidentes en el siglo XviII. Más sorprendente aún era el resultado sobre los americanos más pobres/desposeidos, es decir, los de origen africano. La estatura de los esclavos indica que estaban bien nutridos cuando eran adultos jóvenes, pero no cuando eran niños. Los varones esclavos adultos llegaban a medir 67 pulgadas, es decir, estaban a menos de una pulgada de los blancos nacidos en el norte y por encima de las normas europeas contemporáneas. En realidad, su estatura física se aproximaba más a la de los aristócratas europeos que a la de los campesinos europeos. A pesar de su degradación social, los negros nacidos en el Nuevo Mundo eran sistemáticamente más altos que sus hermanos nacidos en África, tanto en el siglo XVIII como en el XIX, lo cual indica claramente que en el Nuevo Mundo habia abundantes existencias de alimentos ${ }^{3}$.

También merece la pena señalar los resultados europeos. Una cosa es decir a los estudiantes universitarios que la subida de los precios del pan provocó revueltas a finales del siglo XviI, pero otra es poder afirmar que los «Oliver Twist» de Londres estaban tan desnutridos que apenas hay en el mundo de hoy una población civilizada que tenga una estatura comparable. Una cosa es decir que la distribución de la renta era desigual a principios del siglo XIX en medio de la Revolución Industrial y otra es poder demostrar que a los trece años los chicos de la alta burguesía pertenecientes a la elitista Sandhurst Royal Military Academy eran $19 \mathrm{~cm}$. más altos — casi 8 pulgadas más altos-que sus compatriotas de los barrios bajos de Londres ${ }^{4}$.

Sabíamos cómo eran las insalubres ciudades antes de la Revolución Industrial y en los primeros años, pero actualmente podemos demostrar que si se considera la región que rodea la ciudad de Baltimore (Maryland) o Viena (Baja Austria) o Londres (Inglaterra) o Tokio (Japón), cuanto más lejos se vivía de estos centros urbanos, mayores eran las probabilidades de alcanzar la estatura genética potencial. En otras palabras, en los primeros años de la Revolución Industrial, el encontrarse cerca de la fuente de nutrientes o el ser autosuficiente en la producción de alimentos tenía claras ventajas biológicas. Aunque en

\footnotetext{
2 Robert W. Fogel (1986).

3 Richard Steckel (1986), John Komlos (1990).

4 Roderick Floud, Kenneth Wachter y Annabel Gregory (1990).
} 
las sociedades de mercado modernas generalmente existe una correlación positiva entre la estatura y la renta per cápita, no siempre ha sido así. Hasta el siglo $\mathrm{xx}$, la población rural era invariablemente más alta que la urbana y la población de las regiones subdesarrolladas tendía a estar mejor alimentada que la de las áreas desarrolladas. Por ejemplo, la situación de los irlandeses en lo que a nutrición se refiere era mejor que la de los ingleses industriales y los húngaros eran más altos que los checos. En Estados Unidos, los sureños estaban mejor alimentados que los norteños. En la década de 1830, los agricultores americanos eran más altos que los profesionales urbanos. En otras palabras, la proximidad a las fuentes de alimentos era uno de los factores más importantes en la determinación del bienestar nutritivo de una persona. En general, la producción de alimentos per cápita era más importante en la determinación de la situación nutritiva que la renta monetaria real, porque las personas que compraban los alimentos tenían que pagar los costes de transporte y los esfuerzos de los intermediarios, mientras que no ocurría así con los agricultores que tra. bajaban para su subsistencia. Por lo tanto, en los primeros años de la Revolución Industrial suele observarse la existencia de una relación negativa entre el consumo de alimentos y el nivel de industrialización, lo cual también significa que la integración en el mercado y la expansión de los mercados urbanos suponían una amenaza potencial para la situación de la nutrición al alterar la relación real de intercambio del sector agricola 5 .

El debate sobre la evolución del nivel de vida durante las primeras fases de la Revolución Industrial, en las que el consumo de alimentos todavía representaba nada menos que tres cuartas partes de la renta total en el caso de las clases más bajas, ha acentuado la importancia de la historia antropométrica. El enfoque antropométrico tiene la ventaja de eludir la disputa sobre la exactitud de los índices de salarios reales y toda una multitud de problemas relacionados con éste, como la manera de convertir correctamente los salarios por hora en rentas familiares anuales.

En este sentido, los resultados más interesantes están relacionados con los ciclos de la estatura humana. La primera recesión registrada tuvo lugar en Europa durante la segunda mitad del siglo XVIII; también hubo otra en Estados Unidos durante las décadas anteriores a la Guerra de Secesión. Ambas fueron acompañadas de un rápido crecimiento de la población, de la urbanización y de la expansión del sector industrial. En ambos casos, el crecimiento relativamente lento de la población activa agrícola y la ausencia de avances tecnológicos en la producción de alimentos, unidos al aumento de la demanda urbana

Joel Mokyr y Cormac Ó Gráda (1988). 
de alimentos, hicieron que el precio de los nutrientes subiera tanto en términos absolutos como en relación con los productos industriales.

Por ejemplo, en Estados Unidos, en el periodo anterior a la Guerra de Secesión, la población urbana casi se duplicó todas las décadas, mientras que la población activa agricola creció menos de un 10 por ciento cada década. No es de extrañar que los precios de los alimentos subieran en términos reales y que disminuyera tanto el consumo de calorias como el de proteínas. El estudiante medio de 18 años que entraba en la West Point Military Academy pesaba algo menos de 128 libras; el 25 por ciento de los cadetes pesaba menos de 110 en las edades próximas a los 20 años. Este peso es inferior al de las niñas actuales. Por lo tanto, a pesar de que el crecimiento económico fue muy rápido en las décadas anteriores a la guerra y de que la renta nacional per cápita aumentó un 40 por ciento entre 1840 y 1870 , la estatura física de la población americana disminuyó durante ese mismo periodo. Estos fueron los costes ocultos de la industrialización incluso en un país abundante en recursos como Estados Unidos, costes que están quedando patentes en la actualidad.

En Europa, la relación entre la Revolución Industrial y el bienestar de las sociedades que la experimentaron es desde hace tiempo una cuestión controvertida. Se conoce con el nombre de debate sobre el nivel de vida.

Actualmente, los historiadores antropométricos han sido capaces de transformar el debate, llevándolo a sus puntos esenciales. Se ha demostrado que la disminución de la estatura humana fue anterior al comienzo de la industrialización en la segunda mitad del siglo xviII y, por lo tanto, que la disminución del bienestar no pudo ser causada por la Revolución Industrial. Es cierto que el nivel de vida continuó empeorando incluso después de que comenzara la Revolución Industrial. Esta pauta ha llevado erróneamente a muchos estudiosos a creer que existía una relación causal entre la Revolución Industrial y el empeoramiento del nivel de vida de las clases más bajas. Actualmente, es evidente, por el contrario, que la causa fue la expansión demográfica que empezó en Europa alrededor de la década de 1730, es decir, antes de la Revolución Industrial, y es razonable suponer que la expansión del sector industrial detuvo el deterioro del bienestar de la sociedad, al generar renta adicional, que pudo utilizarse para importar nutrientes. Sin la Revolución Industrial, la situación nutritiva de la población probablemente se habría deteriorado aún más y los factores que impulsan el crecimiento habrían sido disipados, una vez más, por las presiones demográficas malthusianas como ocurrió en el siglo XIV y posteriormente en el siglo XVII.

Por lo tanto, los indicadores convencionales de los niveles de vida, como los salarios reales o el nivel del producto interior bruto per cápita, han despis- 
tado a los estudiosos interesados por la repercusión de la industrialización y el desarrollo económico en el nivel de vida. Resulta que el culpable último no es la Revolución Industrial, sino la revolución demográfica. Es cierto que la Revolución Industrial no fue capaz de contrarrestar las presiones malthusianas a corto plazo, sólo a largo plazo. Pero puede demostrarse que los niveles de vida han mejorado increiblemente en los dos últimos siglos mostrando, por ejemplo, que la estatura de los chicos ingleses de trece años y de clase baja aumentó cerca de veinte centímetros entre 1790 y 1990 . No cabe duda de que el aumento se ha registrado, en su mayor parte, en los últimos cien años, gracias en parte a la mejora de la salud pública en las áreas urbanas.

$¿ \mathrm{Ha}$ aportado este tipo de investigación nuevos conocimientos? Creemos que sí. Ha explorado el carácter de las tendencias de los niveles de vida relacionado con el sexo, aspecto del debate que se habia dejado totalmente de lado hasta ahora. Por ejemplo, varios estudios han demostrado que el empeoramiento de la nutrición solía afectar antes a las mujeres que a los varones. Este enfoque también ha mostrado que los varones analfabetos eran más bajos que los alfabetizados. Ha demostrado que existen ciclos antropométricos que hasta ahora no se sabía que existian. Actualmente sabemos que los niños esclavos estaban desnutridos y que crecian en las edades próximas a los 20 , acercándose significativamente al resto. Sabemos más sobre el abismo que existía entre el Viejo Mundo y el Nuevo Mundo en lo que se refiere a los niveles nutritivos. Sabemos que los afroamericanos eran más altos que los africanos de África. Sabemos que los aristócratas alemanes eran más altos que los de clase media y que la alta burguesia inglesa disfrutaba de un nivel de vida superior al de sus homónimos alemanes, los cuales, disfrutaban, a su vez, de un mayor bienestar que los nobles austriacos. Se ha demostrado que el nivel de vida biológico puede diverger de los indicadores más convencionales del bienestar durante las primeras etapas de la industrialización y que la renta per cápita puede ser un indicador ambiguo del bienestar durante algunas fases de crecimiento. Se trata de notables aportaciones tanto a la historia social como a la historia económica.

\section{BIBLIOGRAFÍA}

Fogel, R. W. (1986): «Nutrition and the Decline in Mortality Since 1700: Some Preliminary Findings», en S. L. Engerman y R. Gallman, eds., Long Term Factors in American Economic Growth, Chicago, NBER, pp. 439-555. 
Floud, R. Kwachter, y A. Gregory (1990): Height, Health and History, Cambridge, C. V. Komlos, J. (1990): «Height and Social Status in Eighteenth Century Germany», Journal of Interdisciplinary History, 20, pp. 607-621.

- (1989): Nutrition and Economic Development in the Eigbteenth Century Habsburg Monarchy: An Antbropometric History, Princeton, Princeton U. P.

MoKyr, J, y C. OGRADA (1988): «Poor and Getting Poover? Living Standards in Ireland before the Famine», Economic History Review, 41, pp. 209-235.

STECKel, R. (1986): “A Peculiar Population: the Nutrition, Health and Mortality of American Slaves fron Childhood to Naturity», Joumal of Economic History, 46, pp. 721-741.

Traducción de Esther Rabasco y Luis Toharia. 